\title{
Laboratory-scale X-ray absorption spectroscopy approach for actinide research : Experiment at the uranium L3-edge
}

Bès, $R$.

2018-08-15

Bès , R , Ahopelto , T , Honkanen , A-P , Huotari , S , Leinders , G , Pakarinen , J \& Kvashnina , K 2018 , ' Laboratory-scale X-ray absorption spectroscopy approach for actinide research : Experiment at the uranium L3-edge ' , Journal of Nuclear Materials, vol. 507 , pp. 50-53 . https://doi.org/10.1016/j.jnucmat.2018.04.034

http://hdl.handle.net/10138/314228

https://doi.org/10.1016/j.jnucmat.2018.04.034

cc_by_nc_nd

acceptedVersion

Downloaded from Helda, University of Helsinki institutional repository.

This is an electronic reprint of the original article.

This reprint may differ from the original in pagination and typographic detail.

Please cite the original version. 


\section{Accepted Manuscript}

Laboratory-scale X-ray absorption spectroscopy approach for actinide research:

Experiment at the uranium $\mathrm{L}_{3}$-edge

R. Bès, T. Ahopelto, A.-P. Honkanen, S. Huotari, G. Leinders, J. Pakarinen, K. Kvashnina

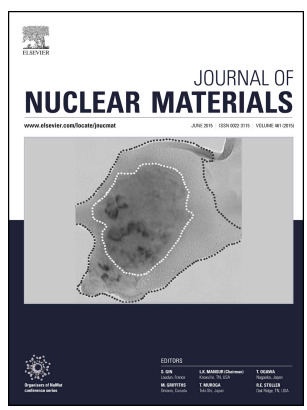

PII: $\quad$ S0022-3115(17)31828-7

DOI: $\quad$ 10.1016/j.jnucmat.2018.04.034

Reference: NUMA 50914

To appear in: Journal of Nuclear Materials

Received Date: 22 December 2017

Revised Date: 26 March 2018

Accepted Date: 19 April 2018

Please cite this article as: R. Bès, T. Ahopelto, A.-P. Honkanen, S. Huotari, G. Leinders, J. Pakarinen, K. Kvashnina, Laboratory-scale X-ray absorption spectroscopy approach for actinide research: Experiment at the uranium L3-edge, Journal of Nuclear Materials (2018), doi: 10.1016/j.jnucmat.2018.04.034.

This is a PDF file of an unedited manuscript that has been accepted for publication. As a service to our customers we are providing this early version of the manuscript. The manuscript will undergo copyediting, typesetting, and review of the resulting proof before it is published in its final form. Please note that during the production process errors may be discovered which could affect the content, and all legal disclaimers that apply to the journal pertain. 


\title{
Laboratory-scale X-ray absorption spectroscopy approach for actinide research: experiment at the uranium $\mathrm{L}_{3}$-edge.
}

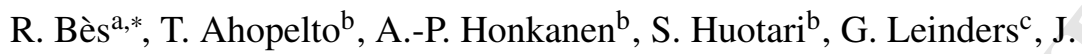 \\ Pakarinen $^{\mathrm{c}}$, K. Kvashnina ${ }^{\mathrm{d}, \mathrm{e}}$ \\ ${ }^{a}$ Department of Applied Physics, Aalto University, P.O. Box 14100, FI-00076 Aalto, Finland \\ ${ }^{b}$ Department of Physics, University of Helsinki, P.O. Box 64, FI-00014 Helsinki, Finland \\ ${ }^{c}$ Belgian Nuclear Research Centre (SCK.CEN), Institute for Nuclear Materials Science, Boeretang \\ 200, B-2400 Mol, Belgium \\ ${ }^{d}$ Rossendorf Beamline at ESRF - The European Synchrotron, CS40220, 38043 Grenoble Cedex 9, \\ France \\ ${ }^{e}$ Helmholtz Zentrum Dresden-Rossendorf (HZDR), Institute of Resource Ecology, P.O. Box 510119, \\ 01314 Dresden, Germany
}

\begin{abstract}
We report that by using crystal optics and laboratory-based X-ray source, one may perform easily X-ray Absorption Spectroscopy (XAS) state-of-the-art measurements at the $\mathrm{U} \mathrm{L}_{3}$-edge. Our results are in excellent agreement with synchrotronbased studies for $\mathrm{UO}_{2}, \mathrm{KUO}_{3}$ and $\beta-\mathrm{UO}_{3}$. The laboratory scaled approach constitutes an inexpensive solution to the limited availability of the XAS beamlines for actinide research. Moreover, our results allow for the development of many future applications addressing actinide f-electron chemistry and nuclear energy-related physico-chemistry, such as advanced nuclear fuel development and safe long term disposal of nuclear wastes.
\end{abstract}

\footnotetext{
${ }^{*}$ Corresponding author

Email address: rene. bes@aalto.fi (R. Bès)
} 


\section{Introduction}

X-ray Absorption Spectroscopy (XAS) is a well established non destructive method for determining both the oxidation state and the local environment of a given element in the studied compound. Major strengths of this technique include that no special sample preparation is usually required, and that it is bulk sensitive due to the long penetration depth of X-rays in matter. The sensitivity of XAS to the local order makes it useful not only for crystalline materials but also for liquids, gases, or amorphous matter. For example, XAS is regularly applied in actinide research such as actinide chemistry in molten salts [1], nuclear fuels [2,3], nuclear waste [4] and environmental [5] studies. Indeed, by taking the advantage of the long penetration depth of the X-rays, XAS allows measurements under highly constraining environments and especially when studying radioactive matter such as actinide bearing materials.

XAS experiment requires a monochromatic and tunable X-ray beam. After the advent of synchrotron radiation sources, XAS experiments strongly focused at using synchrotron facilities for the obvious advantages of synchrotron light, most important difference to conventional x-ray sources being the several orders of magnitude higher brightness. However, the limited access to synchrotron beamtime access reduces and nearly excludes a large number of potentially important scientific research to be performed. This is especially true for actinide research, which at synchrotrons requires dedicated beamlines, and specific authorizations. Furthermore, high costs of radioactive sample transport and the limited number of dedicated beamlines strongly limits the experimental possibilities. In Europe, only few beamlines are clearly dedicated to actinide research: the MARS beamline [6] at the French synchrotron radiation facility SOLEIL (Saint Aubin, France), the ROBL beamline [7] at the European Synchrotron Radiation Facility (ESRF, 
Grenoble, France), and the INE [8] and CAT-ACT beamlines [9] at the ANKA synchrotron radiation facility at the Karlsruhe Institute of Technology (KIT, Karlsruhe, Germany). Consequently, the development of alternatives is mandatory to compensate the currently lacking beamtime.

Studies of the XAS fine structure using conventional x-ray sources started rather soon after the discovery of x-rays [10], and in the mid-1970's the advent of synchrotron storage rings as X-ray sources made several advances in the XAS as a technique. However, XAS using laboratory-based sources and crystal optics have been continuously reported until today [11-21], because even owing to less intense $\mathrm{x}$-ray source, the ability to perform experiments in home laboratory setting is convenient for many reasons such as easier access. Especially the recent development in SBCA optics [19, 22-24] has improved the quality of such spectrometers now considerably. Typical geometries are of Von Hamos and Johansson and Johann types using cylindrically $[11-18,20]$ and spherically $[19,21]$ bent analyzer crystals (CBCA and SBCA respectively). Compared to CBCA, SBCA's offer a relatively larger collection solid angle and a better resolution in the hard x-ray regime depending on the considered configuration and energy range [19]. Most of the reported laboratory scale XAS devices covers energies ranging between 5 and $12 \mathrm{keV}$, which do not include the actinide M and L-edges. However, the Mo K-edge (about $20 \mathrm{keV}$ ) obtained using a Laue-type DuMond curved crystal spectrometer [25] or a double-crystal monochromator [26], the Rh K-edge (about 23 $\mathrm{keV}$ ) using a double-crystal monochromator [26] and the Zr K-edge (about 18 $\mathrm{keV}$ ) collected using a transmission dispersive arrangement [27] can be found in literature. Therefore, the actinide L-edges are, in principle, reachable, and studies using them have already been done at Los Alamos National Laboratory [28] with an SBCA and Rowland-circle geometry instrument similar to the one here and by [19], but not reported in literature. Despite the obvious need of actinide L-edges for 
routine experiment in nuclear material research or radiochemistry dedicated laboratories, the absence of publication in the field has strongly limited the promotion of the technique to the researchers in the field, leaving the synchrotron radiation facility without alternative. In this work we finally report that by using efficient and cost-effective crystal optics, following the recent designs of Seidler et al. [19] with laboratory-based sources as an alternative to synchrotron XAS measurement at the uranium $\mathrm{L}_{3}$-edge, i.e. between 17 and $18 \mathrm{keV}$, one may perform easily routine experiments. It is foreseen that this demonstration is highly valuable for further development of laboratory-scale XAS addressing actinide f-electron chemistry and nuclear energy-related physico-chemistry, such as advanced nuclear fuel development and safe long term disposal of nuclear waste.

\section{Material and experimental methods}

\subsection{Sample preparation}

All samples were prepared from depleted nuclear grade $\mathrm{UO}_{2+x}$, supplied by FBFC International (Dessel, Belgium). Assessment of the impurity content of this powder has been reported elsewhere [29]. Sample processing parameters for various samples were determined via simultaneous thermal analysis (Netzsch STA 449 F1 Jupiter). A short description regarding the chosen parameters is given below for clarity [30].

The preparation of $\mathrm{UO}_{2.00}$ was realized by reducing the supplied $\mathrm{UO}_{2+x}$ powder down to stoichiometry by heating it at $700^{\circ} \mathrm{C}$ under a flow of an $\mathrm{Ar} / \mathrm{H}_{2}$ (96:4 vol

$\%$ ) mixture. $\mathrm{KUO}_{3}$ was prepared by mixing stoichiometric amounts of $\mathrm{U}_{3} \mathrm{O}_{8}$ and $\mathrm{K}_{2} \mathrm{CO}_{3}$ (Sigma-Aldrich, Belgium) powders and annealing at $800^{\circ} \mathrm{C}$ for $10 \mathrm{~h}$ under reducing conditions. A wet-chemical route was employed to produce $\beta-\mathrm{UO}_{3}$. Asreceived $\mathrm{UO}_{2+x}$ powder was first dissolved in nitric acid and subsequently titrated 
with an excess of ammonia aqueous solution, which results in precipitation of ammonium diuranate (ADU). $\beta$-UO $\mathrm{UO}_{3}$ was then obtained by calcining the ADU powder at $550^{\circ} \mathrm{C}$ for $30 \mathrm{~min}$.

Phase purity of all samples was confirmed via X-ray diffraction. About 30-50 $\mathrm{mg}$ of compound powders were intimately mixed with boron nitride powder and pressed into thin pellets. These pellets were then doubly confined in kapton and polyethylene.

\subsection{Synchrotron radiation experiments}

X-ray Absorption Near Edge Structure (XANES) were first measured at the Rossendorf Beamline (ROBL, BM20) [7] located at the European Synchrotron Radiation Facility (ESRF, Grenoble, France). The storage ring operating conditions were $6.0 \mathrm{GeV}$ and 170-200 mA. A double-crystal monochromator mounted with a $\mathrm{Si}(111)$ crystal coupled to collimating and focusing Rh-coated mirrors was used. $\mathrm{U} \mathrm{L}_{3}$-edge (17.166 keV) XANES spectra of all samples were recorded in transmission mode between 17 and $17.3 \mathrm{keV}$. The energy calibration was carried out measuring an $\mathrm{Y}$ foil (K-edge, $17.038 \mathrm{keV}$ ) in transmission mode simultaneously with each sample. A step size of $0.75 \mathrm{eV}$ was used in the edge region. The energy $\mathrm{E}_{0}$ of the edge absorption threshold position was taken at the first inflection point of each spectrum by using the first node of the second derivative. Several acquisitions were performed on the same sample and summed up to improve the signal to noise ratio. However, the spectra presented here are for comparison purposes, and contain only 4 scans of approximatively $30 \mathrm{~min}$ each. The ATHENA software (Version 0.9.18) [31] was used to remove the background and to normalize the spectra.

\subsection{Laboratory-scale experiments}

The benchtop XAS instrumentation at University of Helsinki is based on the use of SBCA which allows simultaneous monochromation and focus of the X-ray 
beam to the sample. The schematic of the set-up [32], similar to the one presented in [19] is shown in Figure 1.

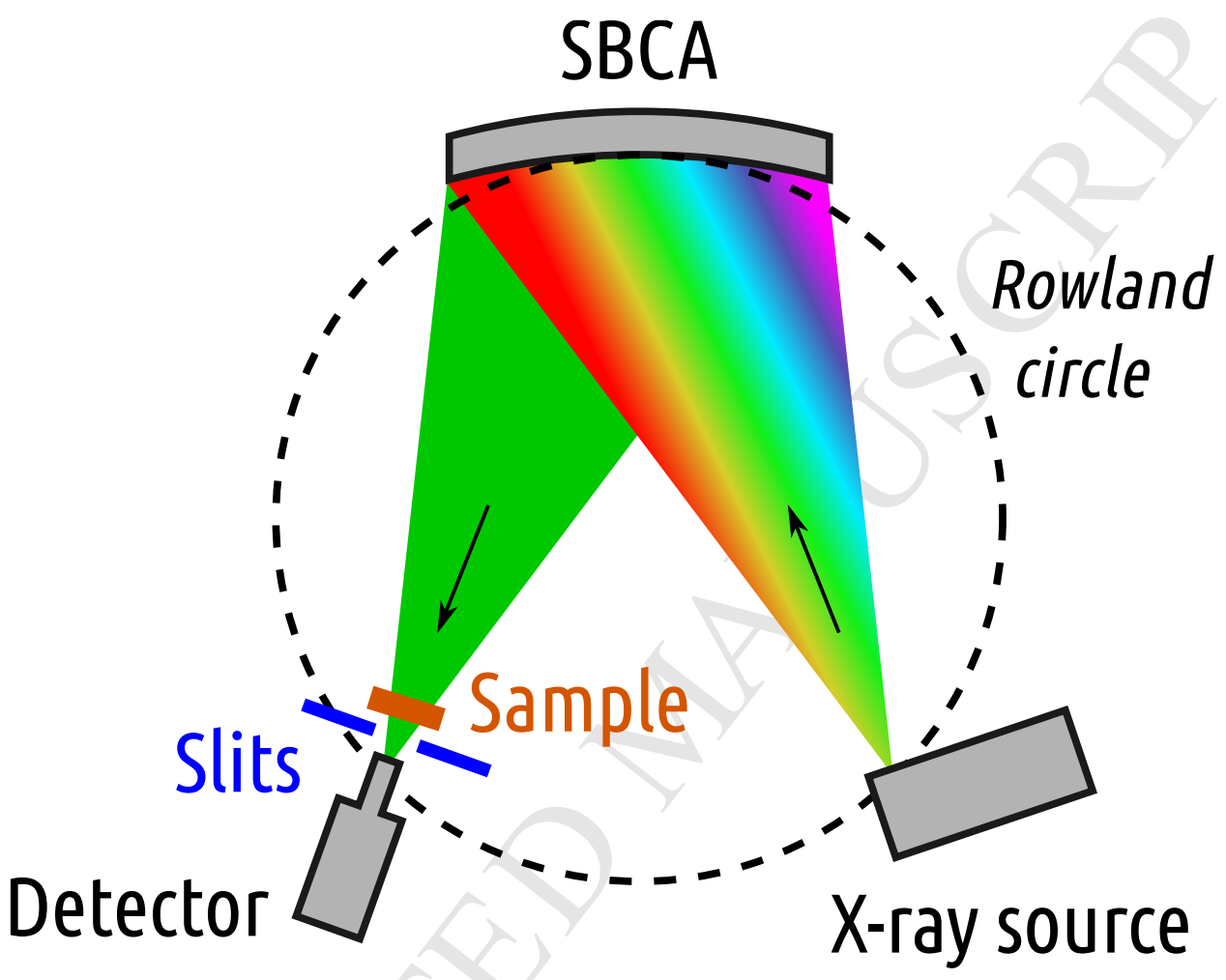

Figure 1: Laboratory scale instrument principles and configuration as for X-ray Absorption Spectroscopy.

The sample, the X-ray source, and the SBCA are positioned on the Rowland circle. When scanning the energy, both crystal and sample move synchronously to track the corresponding Rowland circle. The broadband $\mathrm{x}$-ray radiation from the laboratory X-ray source directly illuminates the SBCA which monochromatizes and focuses the corresponding wavelength into the sample. Slits are applied to reduce the ambient X-ray background arising from elastic scattering and to limit the undesired wavelengths for hitting the sample. Then, the detector collects only 
the X-rays transmitted through the sample.

The X-ray source was a fine-focus Ag anode X-ray tube (Seifert/XRD Eigenmann) with $0.4 \times 0.8 \mathrm{~mm}^{2}$ effective source size (Horizontal x Vertical). The accelerating potential and electron current was fixed to $30 \mathrm{kV}$ and $10 \mathrm{~mA}$, respectively. A CdTe detector (Amptek XR-100T) with an active area of approx. $3 \mathrm{~mm}$ in diameter was used. An integrated signal electronic processing including Multi-Channel Analyser (Amptek, Inc.) was coupled to the detector. The good energy resolution of the CdTe solid-state detector allowed to reject the unwanted Ge(nnn) harmonics other than $\mathrm{n}=9$. A Johann type Ge(111) SBCA, from XRS TECH LLC. [22], with the bending radius of $0.5 \mathrm{~m}$ was used to monochromatize and focus the radiation. Using that X-ray source-SBCA configuration, good count rates were achieved for energies above $12 \mathrm{keV}$ as reported in Table 1 . These count rates allow to measure slightly diluted uranium samples in transmission mode in still reasonable time. However, the fluorescence mode seems still out of reach at actinide L-edges. In addition, other actinides $\mathrm{L}_{3}$-edges and Tc K-edge will be also possible.

The $\mathrm{U} \mathrm{L}_{3}$-edge (17.166 keV) XANES spectra of all samples were recorded in transmission mode between 17 and $17.3 \mathrm{keV}$. This energy range corresponds to the (999) reflection of the Ge(111) SBCA with Bragg angle between $81^{\circ}$ and $86^{\circ}$. The intensity of lower harmonics were intentionally suppressed or reduced using Al filter, in order to not saturate the detector with undesirable counts. The XANES spectra reported here have been collected during 24 hours by repeating 30 min long scans.

The energy dependence of the incident flux can be determined by removing the sample and repeating the energy scan [19]. However, we found impossible subtract efficiently the additional background created by the elastic and inelastic scattering occurring to the doubly confined sample holder, making the standard procedure difficult in our case. To overcome this difficulty, one solution consists in placing 
Table 1: Count rates measured at sample position for energies above $12 \mathrm{keV}$. Note that these count rates are here order of magnitude due to the effect of high deadtime and degraded energy resolution when the detector was placed in direct beam, i.e. in the absence of any sample.*The count rate for the $\mathrm{Ge}\left(1313\right.$ 13) harmonic was measured below the energy range were $\mathrm{X}$-ray source $\mathrm{Ag} \mathrm{K} \beta_{3}$ and $\mathrm{Ag}$ $\mathrm{K} \beta_{1}$ fluorescence lines at $24.910 \mathrm{keV}$ and $24.941 \mathrm{keV}$ respectively were found.

\begin{tabular}{|c|c|c|}
\hline Used harmonic & Energy (keV) & Count rate $\left(\mathrm{s}^{-1}\right)$ \\
\hline $\mathrm{Ge}(777)$ & 13.4 & 1600 \\
\hline 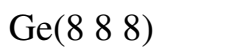 & 15.3 & 2400 \\
\hline $\mathrm{Ge}(999)$ & 17.2 & 700 \\
\hline $\mathrm{Ge}\left(\begin{array}{llll}1 & 11 & 11\end{array}\right)$ & 21.0 & \\
\hline 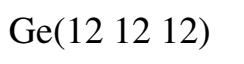 & 22.9 & 100 \\
\hline $\mathrm{Ge}(131313)$ & 24.8 & 20 \\
\hline
\end{tabular}

the sample directly in front of the X-ray source. In our case, we developed another method which relies on the presence of harmonics in the incoming beam as shown in Figure 2. With this approach the acquisition no longer requires repeating the experiment without the sample to obtain the incident-beam spectrum. Assuming that in the absence of a sample, both $\mathrm{Ge}(888)$ and $\mathrm{Ge}(999)$ harmonics behave similarly upon the probed Bragg angle range, one can simultaneously measure the incoming beam intensity and the $\mathrm{UL}_{3}$-edge absorption spectra. In the absence of any edge or variations of the incident-beam spectrum at the energy range covered by the chosen harmonics, absorption decreases linearly with energy increase which justifies the validity of our approach. Such validity is clearly demonstrated by the comparison of harmonics behaviour relatively to $\mathrm{Ge}(888)$ with and without sample as shown in Figure 3. These intensities have been deduced by fitting the different harmonics

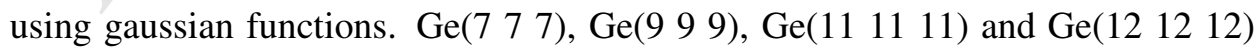
harmonics behave linearly relatively to $\mathrm{Ge}\left(\begin{array}{l}8 \\ 8\end{array}\right)$ as a function of energy without 


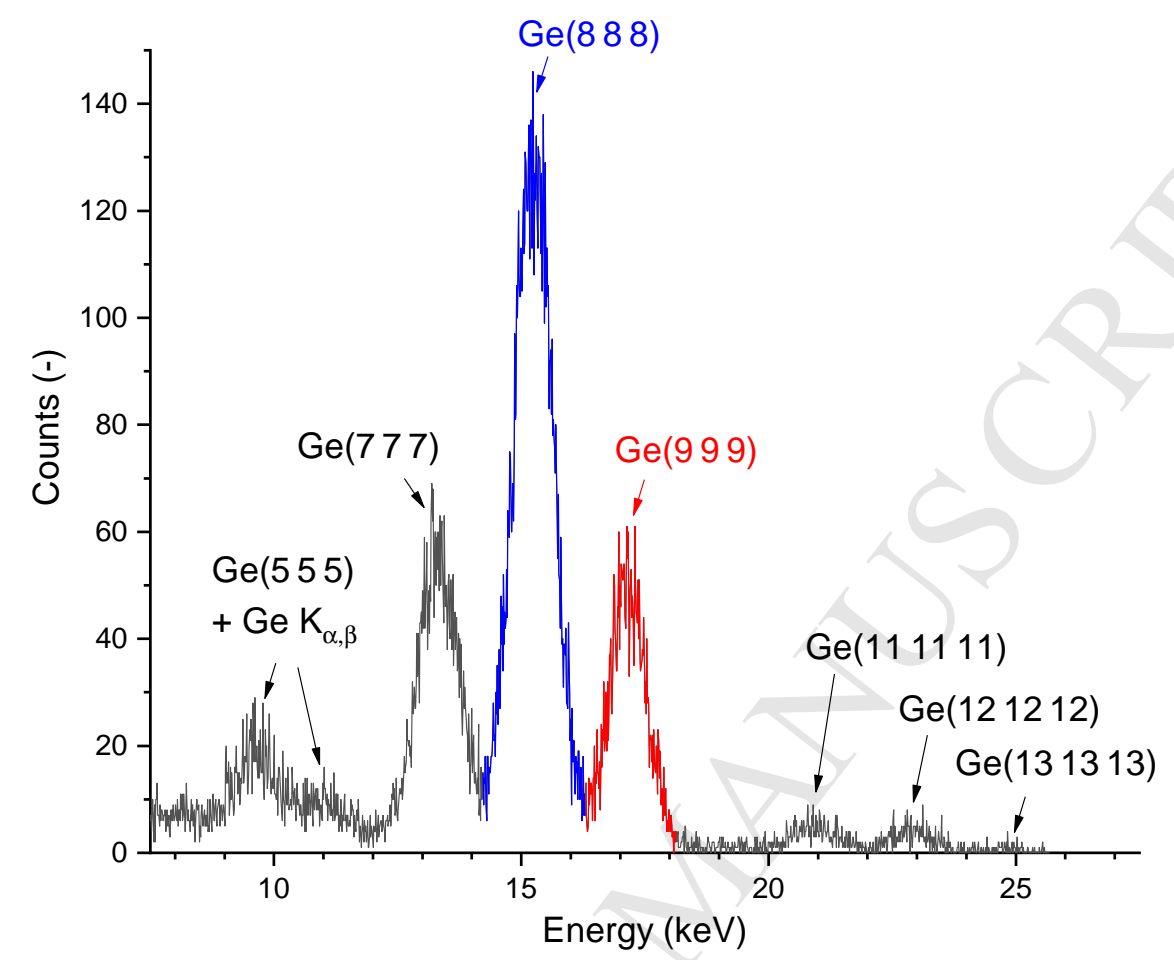

Figure 2: X-ray spectra of the incoming beam collected through the slits, without any sample. The different harmonics due to the Ge crystal as well as the resulting Ge fluorescences are also indicated. The Ge(888) reflection (in blue) was used as a measure of the incoming beam intensity while the $\mathrm{Ge}(999)$ reflection (in red) was the interesting signal.

sample. With a sample, for instance $\mathrm{UO}_{2}$ here, the Uranium $\mathrm{L}_{3}$-edge and $\mathrm{L}_{2}$-edge are clearly visible through the $\mathrm{Ge}(999)$ and $\mathrm{Ge}(111111)$ behaviours respectively. In both cases, the $\mathrm{Ag} \mathrm{K} \beta_{3}$ and $\mathrm{K} \beta_{1}$ fluorescence lines at $24.910 \mathrm{keV}$ and 24.941 $\mathrm{keV}$ are seen through the $\mathrm{Ge}(131313)$ behaviour.

\section{Results and discussion}

Uranium $\mathrm{L}_{3}$-edge XANES spectra for $\mathrm{UO}_{2}, \mathrm{KUO}_{3}$ and $\beta$ - $\mathrm{UO}_{3}$ were collected using both the laboratory-scale set-up and the ROBL beamline at ESRF. They are 


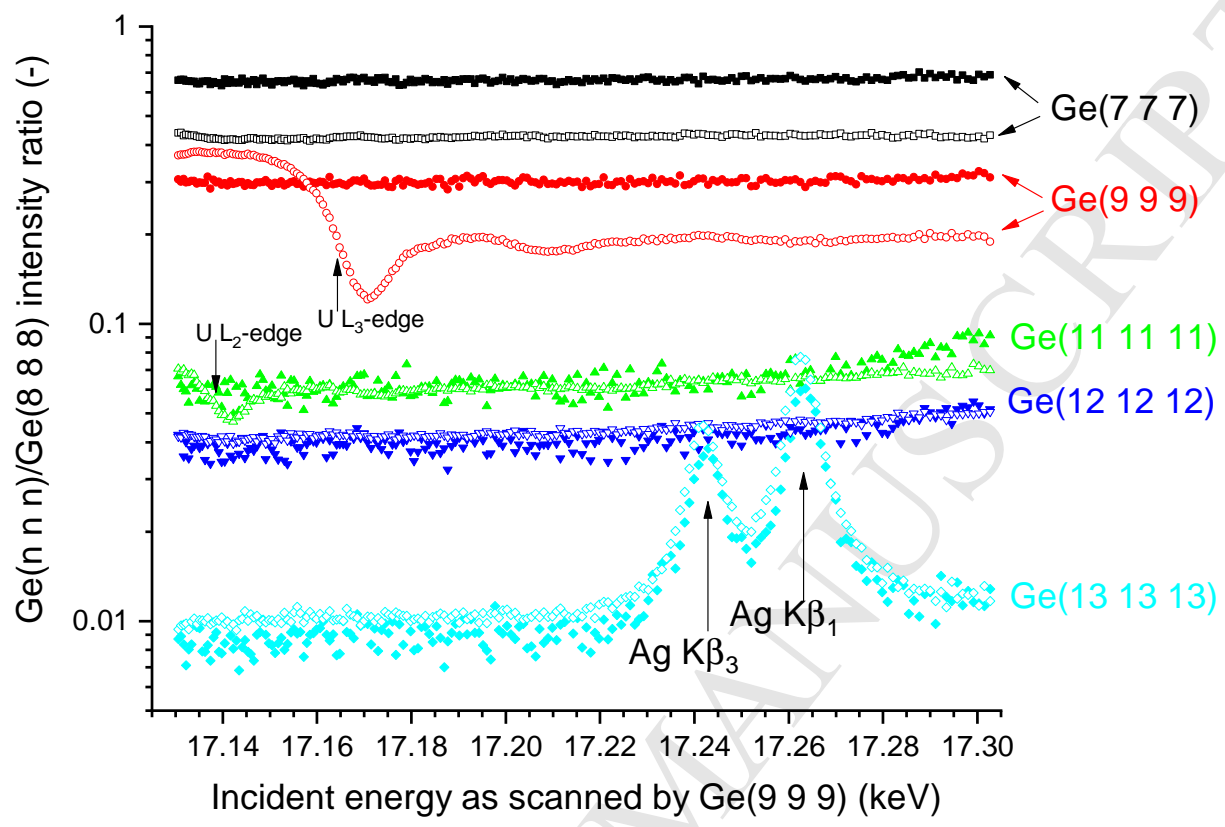

Figure 3: Harmonic $\mathrm{Ge}(\mathrm{n} n \mathrm{n}) / \mathrm{Ge}(8 \mathrm{8} 8)$ intensity ratio as scanned during the experiment with (open symbols) and without (closed symbols) the $\mathrm{UO}_{2}$ sample.

shown in Figure 4. The Uranium $\mathrm{L}_{3}$-edge XANES spectra are usually composed of one intense peak, the so-called white line, and additional resonance and/or shoulders at different energies. Both energy position and intensity of the white-line and the resonances depend on the uranium oxidation states and uranium local environment, i.e. the nature, number and geometrical arrangement of the neighbouring atoms.

The two datasets are in excellent agreement. Most notably, all the spectral features are well reproduced for all samples when using the lab-scale instrumentation. Statistical noise is clearly more pronounced in the laboratory-scale XAS spectra as compared to the synchrotron-XAS. The noise originates from several orders of 


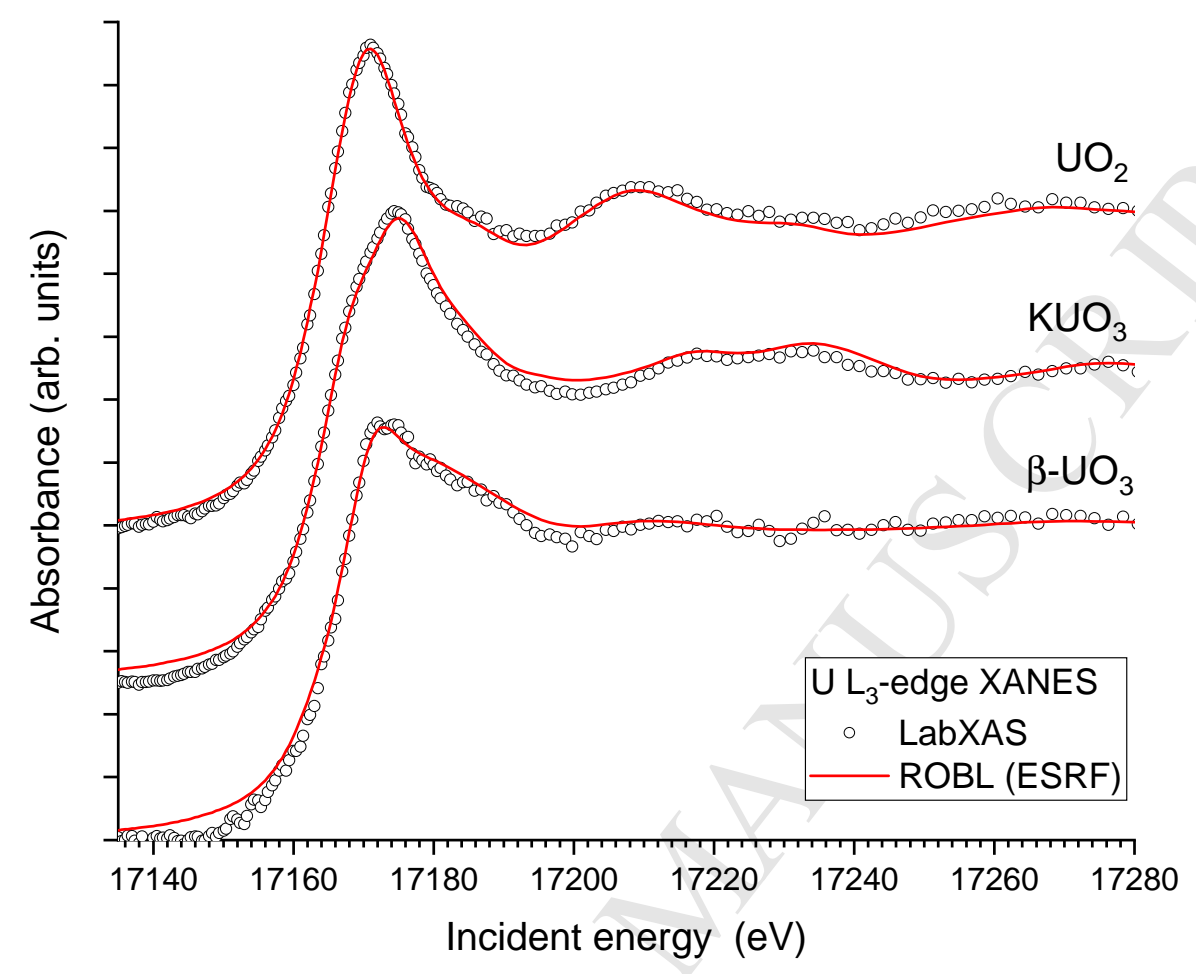

Figure 4: Uranium $\mathrm{L}_{3}$-edge XANES spectra obtained for $\mathrm{UO}_{2}, \mathrm{KUO}_{3}$ and $\beta$ - $\mathrm{UO}_{3}$ and collected in transmission mode using both the laboratory-scale set-up (open symbols) and the ROBL beamline at ESRF (full lines). The spectra are vertically shifted for clarity.

magnitude photon flux difference between synchrotron radiation and standard Xray tube source, which is not completely compensated by longer integration time per spectra. However, collection time is not a limiting factor for laboratory experiments and further improvements are expected when it is increased. One can also observe a slight discrepancy in the pre-edge region for some of the samples arises from ineffective background subtraction. Indeed, we found the $\operatorname{Ge}\left(\begin{array}{lll}8 & 8 & 8\end{array}\right)$ signal being sensitive to the confinement layers and to any slight misalignment between the slits-sample-detector and the SBCA focal point. Improvements are currently being developed, e.g. additional shielding and new sample holder design to min- 
imize this discrepancy in the spectra. Nonetheless, the results between these two XAS methods are comparable and clearly demonstrate the proof of principle for laboratory-scale XAS set-up in actinide research.

While the low photon flux in our laboratory-scale XAS device increases the statistical noise, it also allows measurements for radiation-sensitive samples. There are also possibilities to highly dedicated sample environments for e.g. in-situ measurements. The laboratory-scale XAS device is also an ideal solution for preliminary investigations prior to synchrotron experiments. This approach will strongly benefit the actinide research in the dedicated facilities worldwide in the near future.

\section{Conclusion}

We have reported that measuring $\mathrm{U} \mathrm{L}_{3}$-edge XANES in transmission mode at laboratory-scale constitutes a credible, efficient and affordable alternative to synchrotron for actinide research by avoiding the high costs and lack of beamtime associated with such facilities. We found an excellent agreement with the synchrotron-based studies using reasonable acquisition time. Improvement and optimization of the described experimental device are currently ongoing to ensure faster acquisition and lower statistical noise in the near future, but the approach described here can be already applied in other laboratories for routine experiments. Consequently, the versatile laboratory-scale XAS device complements the synchrotron radiation experiments, allowing many applications to be developed in the field of actinide research, including f-electron chemistry and nuclear energy physico-chemistry, such as advanced nuclear fuel development and long term disposal of nuclear waste. 


\section{Acknowledgements}

The authors thank the ROBL beamline at ESRF for provision of beamtime and for sharing the $\mathrm{Ge}(111)$ analyser crystal, making possible the laboratory scaled experiments. This work has been partially funded by the Academy of Finland, through the project number 227193. We warmly thank Prof. G. Seidler from the University of Washington for fruitful and stimulating discussions.

[1] C. Bessada, D. Zanghi, O. Pauvert, L. Maksoud, A. Gil-Martin, V. SarouKanian, P. Melin, S. Brassamin, A. Nezu, and H. Matsuura, Journal of Nuclear Materials 494 (2017) 192.

[2] D. Prieur, P. Martin, F. Lebreton, T. Delahaye, D. Banerjee, A.C. Scheinost, and A. Jankowiak, Journal of Nuclear Materials 434 (2013) 7.

[3] R. Bès, J. Pakarinen, A. Baena, S. Conradson, M. Verwerft, and F. Tuomisto, Journal of Nuclear Materials 489 (2017) 9.

[4] M.A. Denecke, Coordination Chemistry Reviews 250 (2006) 730.

[5] M. Maloubier, H. Michel, P.L. Solari, P. Moisy, M.-A. Tribalat, F.R. Oberhaensli, M.Y. Dechraoui Bottein, O.P. Thomas, M. Monfort, C. Moulin, and C. Den Auwer, Dalton Transaction 44 (2015) 20584.

[6] B. Sitaud, P.L. Solari, S. Schlutig, I. Llorens, and H. Hermange, Journal of Nuclear Materials 425 (2012) 238.

[7] W. Matz, N. Schell, G. Bernhard, F. Prokert, T. Reich, J. Claußner, W. Oehme, R. Schlenk, S. Dienel, H. Funke, F. Eichhorn, M. Betzl, D. Pröhl, U. Strauch, G. Hüttig, H. Krug, W. Neumann, V. Brendler, P. Reichel, M. A. Denecke and H. Nitsche, Journal of Synchrotron Radiation 6 (1999) 1076. 
[8] K. Dardenne, B. Brendebach, M.A. Denecke, X. Liu, J. Rothe, and T. Vitova, Journal of Physics: Conference Series 109 (2009) 012037.

[9] A. Zimina, K. Dardenne, M. A. Denecke, J. D. Grunwaldt, E. Huttel, H. Lichtenberg, S. Mangold, T. Pruessmann, J. Rothe, R. Steininger, and T. Vitova, Journal of Physics: Conference Series 712 (2016) 012019.

[10] R. Stumm von Bordwehr, Ann. Phys. Fr. 14 (1989) 377.

[11] G.S. Knapp, H. Chen, and T.E. Klippert, Review of Scientific Instruments 49 (1978) 1658.

[12] G.G. Cohen, D.A. Fisher, J. Colbert, and N.J. Shevchik, Review of Scientific Instruments 51 (1980) 273.

[13] P. Georgopoulos and G.S. Knapp, Journal of Applied Crystallography 14 (1981) 3.

[14] W. Thulke, R. Haensel, and P. Rabe, Review of scientific instruments 54 (1983) 277.

[15] K. Tohji, Y. Udawaga, T. Kawasaki, and K. Masuda, Review of scientific instruments 54 (1983) 1482.

[16] A. Williams, Review of scientific instruments 54 (1983) 193.

[17] Y.N. Yuryev, H.-J. Lee, H.-M. Park, Y.-K. Cho, M.-K. Lee, and K.J. Pogrebitsky, Review of scientific instruments 78 (2007) 025108.

[18] Y.N. Yuryev, H.-J. Lee, J.-H. Kim, Y.-K. Cho, M.-K. Lee, and K.J. Pogrebitsky, X-ray spectrometry 37 (2008) 476. 
[19] G.T. Seidler, D.R. Mortensen, A.J. Remesnik, J.I. Pacold, N.A. Ball, N. Barry, M. Styczinski, and O.R. Hoidn, Review of scientific instruments 85 (2014) 113906.

[20] Z. Németh, J. Szlachetko, É. G. Bajnóczi, and G. Vankó, Review of Scientific Instruments 87 (2016) 103105.

[21] D.R. Mortensen, G.T. Seidler, A.S. Ditter, and P. Glatzel, Journal of Physics: Conference Series 712 (2016) 012036.

[22] XRStech webpage: http://xrstech.com/

[23] R. Verbeni, M. Kocsis, S. Huotari, M. Krisch, G. Monaco, F. Sette, and G. Vanko, Journal of Physics and Chemistry of Solids 66 (2005) 2299.

[24] M. Rovezzi, C. Lapras, A. Manceau, P. Glatzel, and R. Verbeni, Review of Scientific Instruments 88 (2017) 013108.

[25] M. Szlachetko, M. Berset, J.-Cl. Dousse, J. Hoszowska, and J. Szlachetko, Review of scientific instruments 84 (2013) 093104.

[26] K. Tohji, Y. Udagawa, T. Kawasaki, and K. Miano, Review of scientific instruments 59 (1988) 1127.

[27] P. Lecante, J. Jaud, A. Mosset, J. Galy, and A. Burian, Review of scientific instruments 65 (1994) 845.

[28] S.A. Kozimor et al., private communications.

[29] G. Leinders, T. Cardinaels, K. Binnemans, and M. Verwerft, Journal of Nuclear Materials 459 (2015) 135.

[30] G. Leinders, R. Bes, J. Pakarinen, K. Kvashnina, and M. Verwerft, Inorganic Chemistry 56 (2017) 6784. 
[31] B. Ravel and M. Newville, Journal of Synchrotron Radiation 12 (2005) 537.

[32] A.-P. Honkanen, et al., under preparation. 
SBCA

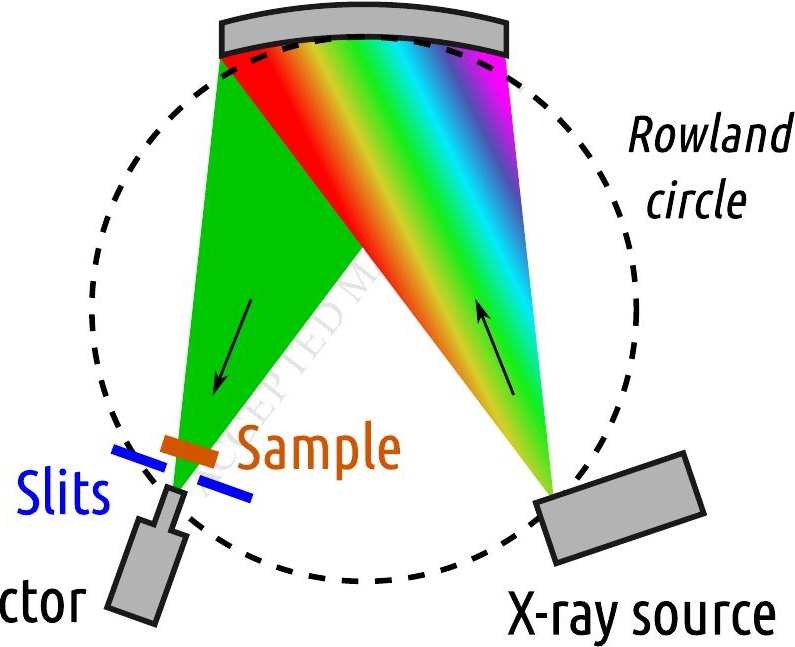




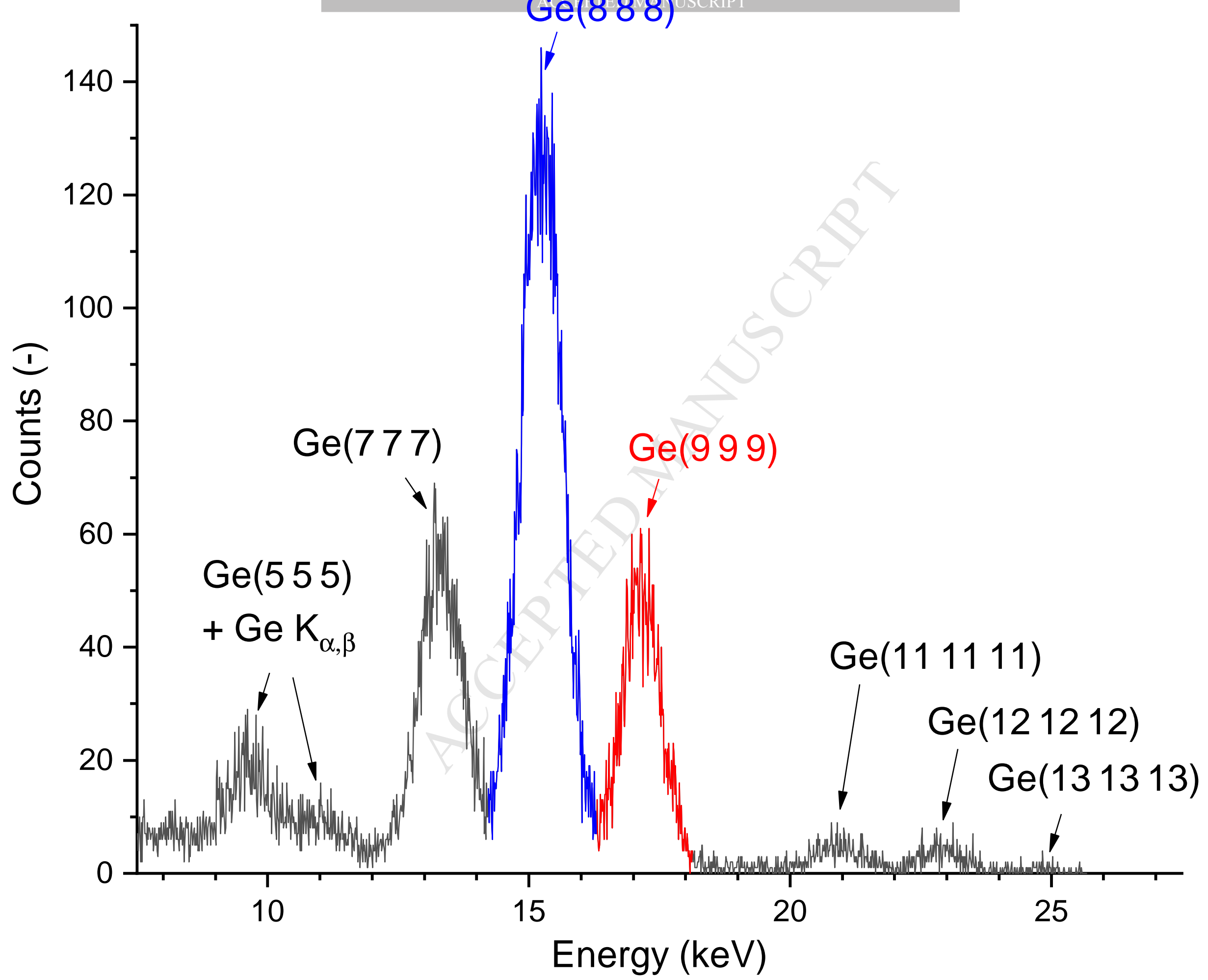




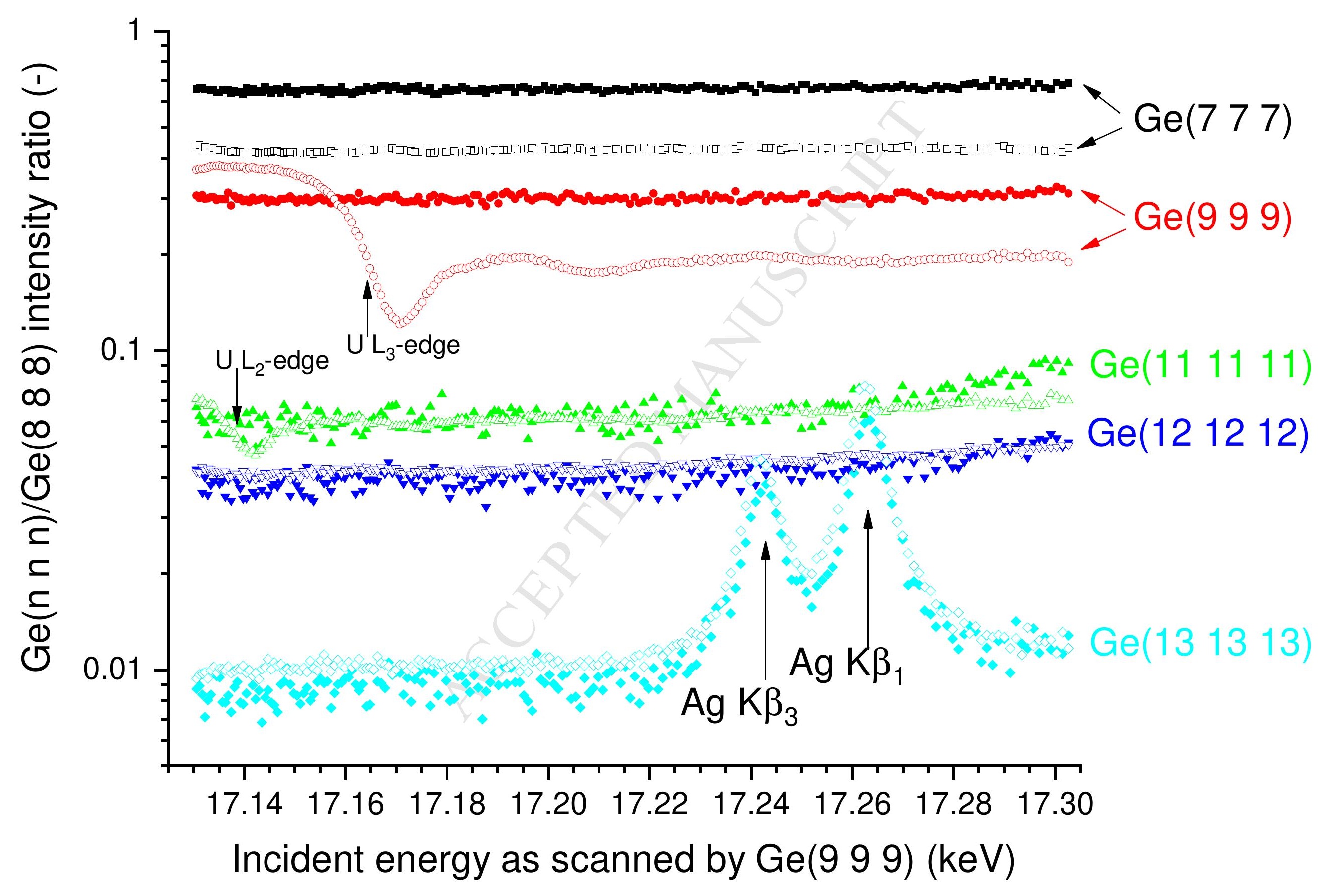




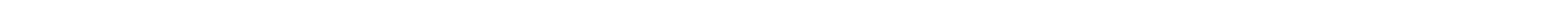

